\title{
Women's views on consent, counseling and confidentiality in PMTCT: a mixed-methods study in four African countries
}

\author{
Anita Hardon ${ }^{1 *}$, Eva Vernooij ${ }^{1}$, Grace Bongololo-Mbera ${ }^{2}$, Peter Cherutich ${ }^{3}$, Alice Desclaux ${ }^{4}$, David Kyaddondo ${ }^{5}$,
} Odette Ky-Zerbo ${ }^{6}$, Melissa Neuman ${ }^{7}$, Rhoda Wanyenze ${ }^{8}$ and Carla Obermeyer ${ }^{9}$

\begin{abstract}
Background: Ambitious UN goals to reduce the mother-to-child transmission of HIV have not been met in much of Sub-Saharan Africa. This paper focuses on the quality of information provision and counseling and disclosure patterns in Burkina Faso, Kenya, Malawi and Uganda to identify how services can be improved to enable better PMTCT outcomes.

Methods: Our mixed-methods study draws on data obtained through: (1) the MATCH (Multi-country African Testing and Counseling for HIV) study's main survey, conducted in 2008-09 among clients ( $\mathrm{N}=408)$ and providers at health facilities offering HIV Testing and Counseling (HTC) services; 2) semi-structured interviews with a sub-set of 63 HIV-positive women on their experiences of stigma, disclosure, post-test counseling and access to follow-up psycho-social support; (3) in-depth interviews with key informants and PMTCT healthcare workers; and (4) document study of national PMTCT policies and guidelines. We quantitatively examined differences in the quality of counseling by country and by HIV status using Fisher's exact tests.
\end{abstract}

Results: The majority of pregnant women attending antenatal care (80-90\%) report that they were explained the meaning of the tests, explained how HIV can be transmitted, given advice on prevention, encouraged to refer their partners for testing, and given time to ask questions. Our qualitative findings reveal that some women found testing regimes to be coercive, while disclosure remains highly problematic. 79\% of HIV-positive pregnant women reported that they generally keep their status secret; only 37\% had disclosed to their husband.

Conclusion: To achieve better PMTCT outcomes, the strategy of testing women in antenatal care (perceived as an exclusively female domain) when they are already pregnant needs to be rethought. When scaling up HIV testing programs, it is particularly important that issues of partner disclosure are taken seriously.

Keywords: PMTCT, Africa, HIV testing, Counseling, Consent, Disclosure

\section{Background}

The 2001 Special Session of the UN General Assembly committed its 189 member states to provide $80 \%$ of pregnant women worldwide with access to Prevention of Mother to Child Transmission of HIV (PMTCT) care by 2010. The aim was to reduce the proportion of infected children born to HIV-positive mothers by $20 \%$ by 2005 , and then by a further $50 \%$ by 2010 . These ambitious

\footnotetext{
* Correspondence: A.P.Hardon@uva.nl

${ }^{1}$ Amsterdam Institute for Social Science Research, University of Amsterdam, Amsterdam, the Netherlands

Full list of author information is available at the end of the article
}

goals have not been met by the majority of countries in Sub-Saharan Africa. When the UN reviewed its progress in 2010 , it was estimated that only $53 \%$ of pregnant women living with HIV in Sub-Saharan Africa had received antiretroviral drugs to prevent mother-to-child transmission [1]. Such findings led to a renewed UN commitment to ensure that "pregnant women have access to antenatal care, information, counseling and other HIV services" [2]. This paper analyzes qualitative and quantitative reports from PMTCT clients to assess the quality of information provision and counseling for PMTCT in Burkina Faso, Kenya, Malawi and Uganda,
C Biomed Central

() 2011 Hardon et al; licensee BioMed Central Ltd. This is an Open Access article distributed under the terms of the Creative Commons Attribution License (http://creativecommons.org/licenses/by/2.0), which permits unrestricted use, distribution, and reproduction in any medium, provided the original work is properly cited. 
and uses these findings to suggest how services can be improved to enable better PMTCT outcomes.

PMTCT was first proposed as a global health policy in the late 1990s [3,4]. Initially, WHO and UNAIDS recommended a three-pillar strategy: to prevent (1) new infections among parents; (2) unwanted pregnancies among HIV-infected women; and (3) transmission from HIVinfected pregnant women and mothers to children [5]. In 2002, a WHO meeting proposed the inclusion of a fourth pillar: to provide care and support to mothers, their infants and their families [5]. These aims were endorsed at the PMTCT High Level Global Partners Forum in Abuja, Nigeria in 2005 [6], by which time global pressure had made antiretroviral treatment available in resource-poor settings.

That PMTCT would not be easy to implement became clear in 2002 when UNICEF conducted pilot studies in 11 countries [7]. In these studies, an average of $30 \%$ of women who visited antenatal care (ANC) sites were not informed about PMTCT. Of those women who did receive information about PMTCT, 30\% did not receive an HIV test. Findings from Kenya and Zambia revealed that one-quarter of tested women did not return for their results. Just over half of the women who tested positive never received prophylactic antiretroviral treatment [7]. These studies were conducted before anti-retroviral treatment became widely available-when being diagnosed with HIV was still equivalent to social ostracism and death in most resource-poor settings.

HIV testing practices have changed dramatically since the advent of large-scale antiretroviral treatment (ART) programs, with provider-initiated HIV testing and counseling programs now commencing many more people on treatment [8]. In the early years of PMTCT in Africa, testing was primarily a tool to prevent transmission to children; in the era of ART scale-up, HIV tests have become gateways to treatment for HIV-positive pregnant women. Testing technologies have also changed. When the UNICEF pilot studies were conducted, PMTCT testing facilities would take blood from patients and send it to laboratories for diagnosis; patients had to return for their results, which partly explained the high dropout rates. Nowadays, nearly all health facilities use rapid testing kits requiring only a finger prick; 30 min later the results are known.

The scaling up of testing and treatment has been accompanied by ethical debates on how best to prepare pregnant women for HIV testing. Some argue that pre-test counseling should be comprehensive-to help clients consciously choose for testing, to prepare for a potential positive outcome, and to disclose and commit to prevention should they be HIV-positive [9]. Proponents of comprehensive counseling fear that routine testing approaches can harm HIV-positive women by exposing them to severe stigma and discrimination, for which they are not prepared. Others suggest that as treatment is now available, HIV tests have become ordinary diagnostic tools, though facilities need to ensure that people feel the freedom to opt out $[10,11]$.

Recent studies in Africa report very high rates of consent for HIV testing within PMTCT programs [12-17]. However, attrition in follow-up continues to be a serious problem [14,18-21]. For example, Manzi et al. found that while $95 \%$ of pregnant women attending antenatal care in Malawi tested for HIV, only $45 \%$ of HIV-positive pregnant women and $34 \%$ of babies born to HIV-positive mothers received ARV prophylaxis [14]. Similarly, Coulibaly et al. found that only $36 \%$ of 1,829 HIV-positive pregnant women in a PMTCT program in Abidjan, Côte d'Ivoire received AZT [20].

Why are so few HIV-positive pregnant women and their infants receiving ARVs? A qualitative study in Malawi unveiled a variety of institutional and cultural factors behind the low uptake of PMTCT: women unprepared for HIV testing and its implications before visiting the antenatal clinic; fear of stigma, discrimination, household conflict and divorce upon disclosure of HIV status; husbands opposed to testing; long waiting times at antenatal clinics; and high transportation costs for follow-up visits [19]. Painter et al. (2004) found underlying mistrust in health facilities and disbelief in test results to be contributing to the low uptake of prophylactic drugs in an antenatal clinic in Abidjan, Côte d'Ivoire [22]. In Kenya, Delva et al. have pointed to the low quality of PMTCT counseling, with crucial topics such as partner involvement and follow-up support covered haphazardly [23]. Creek et al. observed that post-testing counseling in Botswana evaluated pregnant women for ARV therapy but neglected their psycho-social needs [24].

In this paper, we use qualitative and quantitative data to assess (1) the quality of counseling provided to PMTCT clients, (2) how PMTCT clients perceive their freedom to consent to testing, and (3) the challenges they face in disclosing their status to others. We give an overview of national-level PMTCT policy guidelines, and suggest ways in which care provision can be improved.

\section{Methods}

This paper's findings are derived from the MATCH (Multi-country African Testing and Counseling for HIV) study, the first designed to systematically compare client experiences with HIV testing across countries and modes of testing. Numerous government and donor-supported initiatives have been implemented in Burkina Faso, Kenya, Malawi and Uganda, where HIV testing is increasingly conducted within health facilities. The four countries face similar challenges in expanding their testing 
regimes: insufficient resources and infrastructure, shortage of adequately trained staff, and difficulties with referral and follow-up. But there are differences in pace of increase (somewhat slower in Burkina Faso) and in the scale of resources invested (larger in Kenya and Uganda).

The MATCH study included a main survey conducted in 2008-09 among clients and providers at health facilities offering HTC services. The study was conducted in the capital region and one rural province or district in each country, where research teams purposefully selected the facilities to include a variety of types of health facilities. Research teams contacted those in charge at each facility, obtained clearance, and asked them to inform clients about the project. Interviews were planned on at least two different days of the week, with an aim of interviewing a total of 15 clients per facility. On the appointed days, interviewers approached clients, described the study, and invited them to participate. The fraction of respondents to be interviewed at each of the selected facilities was based on the expected numbers of respondents per day: at smaller facilities all clients were invited to participate, whereas at busier facilities, every $n^{\text {th }}$ client was. The teams had to adjust plans when attendance was low, or when health staff did not present at the clinic. While the full MATCH study includes both women and men, and respondents who have and have not tested for HIV, the current paper reports on the MATCH study's findings as they pertain to the subset of women who tested in an antenatal care facility or because of pregnancy.

The MATCH survey was administered in each country by a team of experienced researchers, who were responsible for training field interviewers and data entry staff, and have provided input into the survey design and interpretation of results. Prior to beginning the interview, respondents were told about the study and asked to provide consent. In most cases, written consent or a thumbprint was given by respondents; however, in a few situations where these methods of obtaining consent were deemed unacceptable by the country team, verbal consent was allowed. Field interviewers were project staff, and were not associated with the health facilities where the interviews were conducted. The interviews were conducted in French (Burkina Faso), English (Kenya, Malawi, Uganda) or local languages. The survey questionnaire included closed and open-ended questions and usually lasted from around 30 min to $1 \mathrm{~h}$. Data were collected on respondents' sociodemographic characteristics and their experiences with HIV testing and counseling, using a checklist of interactions and services during pre- and post-test meetings and during follow-up care. Before entering the data into the database, all questionnaires were checked for consistency.

In this paper we describe the experiences of HIV-positive and HIV-negative pregnant women who were tested for HIV. The full MATCH client sample is comprised of
3,660 respondents. Of these, 2,117 respondents were tested for HIV in or after 2007. Out if this sub-set, 421 respondents were PMTCT testers. Women were categorized as PMTCT testers if they either reported testing in an antenatal care facility or cited pregnancy or PMTCT as their reason for testing in an integrated testing and medical facility, such as a hospital or general health clinic. We excluded 13 PMTCT testers with missing HIV status from the analysis. The final sample therefore included 408 women. These women were generally young (in their $20 \mathrm{~s}$ and $30 \mathrm{~s}$ ) with no or only primary education. In Burkina Faso, educational level of the women was lowest: $40.4 \%$ of the respondents had no formal education (see Table 1).

Two kinds of data were collected from this sub-set of 408 women: multiple choice responses to assess their views and experiences of HIV testing, and answers to open-ended questions which gave women an opportunity to expand on their views and experiences of counseling, consent and confidentiality (the 3Cs).

We used guidelines on HIV testing from major international, United States, and European organizations [25-29] to select variables to measure women's views and experiences of the 3Cs. In light of the debate over the extent of necessary pre-test counseling, and the need to tailor posttest counseling to test results [25,26,30], we examined preand post-test counseling separately (see Table 2 ). In addition, the survey included measures for self-stigma, enacted and community stigma from the WHO's manual $H I V$ Testing, Treatment and Prevention: Generic Tools for Operational Research [31], see Table 3. We used Stata 10.1 SE to conduct a descriptive analysis of the $3 \mathrm{Cs}$ and measured significance of differences by country and by HIV status using Fisher's exact tests appropriate for the relatively small sample size with a threshold for significance at $p=0.05$.

We closely examined experiences of stigma, disclosure, post-test counseling and access to follow-up psycho-social support in a sub-set of $63 \mathrm{HIV}$-positive women (6 in Burkina Faso, 8 in Kenya, 34 in Malawi and 15 in Uganda), using primarily their responses to the open-ended question. And, to gain further insight into these issues, we held 14 in-depth interviews with key informants recruited through support groups for HIV-positive individuals and 21 interviews with healthcare workers in PMTCT facilities. To further probe on the experiences of HIV-positive individuals, the teams conducted 20 focus group discussions with members of support groups (7 in Burkina Faso, 6 in Kenya, 5 in Malawi, and 2 in Uganda). The focus group discussions were facilitated by an experienced qualitative researcher. All interviews except the key informant interviews with HIV-positive women attending support groups and the focus group discussions were held in antenatal care facilities. The interviews and focus group discussions were transcribed and analyzed using NVivo 8 software. 
Table 1 Age, educational attainment, household assets, marital status, and number of previous HIV tests by country, PMTCT testers

\begin{tabular}{|c|c|c|c|c|c|c|c|c|c|c|}
\hline & \multicolumn{2}{|c|}{ Burkina Faso } & \multicolumn{2}{|c|}{ Kenya } & \multicolumn{2}{|c|}{ Malawi } & \multicolumn{2}{|c|}{ Uganda } & \multicolumn{2}{|c|}{ Total } \\
\hline & No. & Col\% & No. & Col\% & No. & Col\% & No. & Col\% & No. & Col\% \\
\hline \multicolumn{11}{|l|}{ Age } \\
\hline $18-25$ years & 46 & 44,2 & 21 & 28,8 & 65 & 47,4 & 46 & 50 & 178 & 43,8 \\
\hline $25-34$ years & 55 & 52,9 & 44 & 60,3 & 59 & 43,1 & 40 & 43,5 & 198 & 48,8 \\
\hline $35-44$ years & 3 & 2,9 & 7 & 9,6 & 12 & 8,8 & 6 & 6,5 & 28 & 6,9 \\
\hline 45 years and more & 0 & 0 & 1 & 1,4 & 1 & 0,7 & 0 & 0 & 2 & 0,5 \\
\hline \multicolumn{11}{|l|}{ Education } \\
\hline No formal education & 42 & 40,4 & 0 & 0 & 23 & 16,7 & 8 & 8,7 & 73 & 17,9 \\
\hline Primary incomplete/complete & 36 & 34,6 & 31 & 41,9 & 92 & 66,7 & 43 & 46,7 & 202 & 49,5 \\
\hline Secondary or more & 26 & 25 & 43 & 58,1 & 23 & 16,7 & 41 & 44,6 & 133 & 32,6 \\
\hline \multicolumn{11}{|l|}{ Electricity } \\
\hline No & 68 & 65,4 & 24 & 32,4 & 131 & 94,9 & 46 & 50 & 269 & 65,9 \\
\hline Yes & 36 & 34,6 & 50 & 67,6 & 7 & 5,1 & 46 & 50 & 139 & 34,1 \\
\hline \multicolumn{11}{|l|}{ Plumbing } \\
\hline No & 73 & 70,2 & 30 & 40,5 & 107 & 77,5 & 70 & 76,1 & 280 & 68,6 \\
\hline Yes & 31 & 29,8 & 44 & 59,5 & 31 & 22,5 & 22 & 23,9 & 128 & 31,4 \\
\hline \multicolumn{11}{|l|}{ Flush toilet } \\
\hline No & 102 & 98,1 & 42 & 56,8 & 132 & 95,7 & 87 & 94,6 & 363 & 89 \\
\hline Yes & 2 & 1,9 & 32 & 43,2 & 6 & 4,3 & 5 & 5,4 & 45 & 11 \\
\hline \multicolumn{11}{|l|}{ Marital status } \\
\hline never married & 6 & 5,8 & 10 & 13,5 & 3 & 2,2 & 12 & 13 & 31 & 7,6 \\
\hline married or cohabiting & 94 & 90,4 & 64 & 86,5 & 123 & 89,1 & 78 & 84,8 & 359 & 88 \\
\hline divorced/separated & 3 & 2,9 & 0 & 0 & 8 & 5,8 & 1 & 1,1 & 12 & 2,9 \\
\hline Widowed & 1 & 1 & 0 & 0 & 4 & 2,9 & 1 & 1,1 & 6 & 1,5 \\
\hline \multicolumn{11}{|l|}{ Number of times tested } \\
\hline 1 & 57 & 54,8 & 35 & 47,3 & 66 & 47,8 & 34 & 37 & 192 & 47,1 \\
\hline 2 & 32 & 30,8 & 26 & 35,1 & 43 & 31,2 & 24 & 26,1 & 125 & 30,6 \\
\hline 3 or more & 15 & 14,4 & 13 & 17,6 & 29 & 21 & 34 & 37 & 91 & 22,3 \\
\hline Total & 104 & 100 & 74 & 100 & 138 & 100 & 92 & 100 & 408 & 100 \\
\hline
\end{tabular}

We also reviewed PMTCT policies in the four countries through document study and key informant interviews to determine the guidance given to health workers on how to conduct counseling, and how to confront the challenges of consent, confidentiality and disclosure in pre- and post-test counseling.

The mixed-methods approach of this study allows us to present quantitative measurements as well as qualitative insights on the quality of counseling, consent and confidentiality, and the stigma and disclosure challenges faced by HIV-positive pregnant women. The study was not designed to provide a representative picture of PMTCT implementation in Burkina Faso, Kenya, Malawi and Uganda. It rather aimed to describe policies and practice as experienced by women in antenatal sites and to highlight the issues at stake in further scaling up and increasing access to PMTCT.
The study was reviewed by the ethics committees of the Amsterdam Medical Center of the University of Amsterdam, the World Health Organization, and relevant bodies in each of the four African countries.

\section{Results}

\section{PMTCT testing policies}

The turn towards routine provider-initiated testing has been accompanied by revision of national HIV testing and counseling policies. At the time of our study, all four countries emphasized the principle of informed consent. For example, the 2005 Ugandan policy states that "All HIV testing should be done with the client's knowledge and consent" [32], while the 2008 Kenyan guidelines stress that "No person shall be tested without their consent" [33]. But national policies differ on the role and time allotted to pre-test counseling. The Ugandan policy states 
Table 2 The 3C's variables used in our study

\begin{tabular}{l}
\hline Pre-test counseling \\
\hline Met with counselor before the test \\
\hline Provider explained how HIV is transmitted \\
\hline $\begin{array}{l}\text { Provider explained the meaning of HIV-positive and negative } \\
\text { results }\end{array}$ \\
\hline Given time to ask questions \\
\hline Post-test counseling \\
\hline Received the results \\
\hline Provider explained the meaning of the results \\
\hline Provider gave advice on prevention \\
\hline Provider suggested to discuss status with someone \\
\hline Provider advised partner referral \\
\hline Provider gave time to ask questions \\
\hline Consent \\
\hline Provider asked if respondent agreed to test \\
\hline $\begin{array}{l}\text { Provider explained that respondent had a choice to accept or } \\
\text { refuse }\end{array}$ \\
\hline Confidentiality \\
\hline Provider explained that results would not be shared \\
\hline Respondent believes results have been protected \\
\hline Satisfaction with post-test counseling \\
\hline Received sufficient information \\
\hline Was well treated \\
\hline Thought meeting was useful \\
\hline Referral index (HIV positives only) \\
\hline Prescribed medications \\
\hline Rorred to a support group \\
\hline
\end{tabular}

that counseling should be "comprehensive" unless the extra time required "causes a barrier to testing itself" [32]. In contrast, the 2008 Kenyan policy places less emphasis on pre-test counseling, implying a form of triage practiced post-test, with those found to be HIV-positive entitled to comprehensive post-test counseling. The Malawian and
Burkina Faso policies require pre-test counselors to inform women that they have the right to opt out of testing $[34,35]$. Burkina Faso's national HIV Counseling and Testing $(\mathrm{HCT})$ policy adds that counselors must respect client "autonomy" and understand their reasons for refusing; it recommends improved counseling for more women to accept testing [35].

National policies also differ on confidentiality and disclosure. The 2008 Kenyan HTC policy states that client information cannot be shared without their consent. But the policy-citing evidence that switching from anonymous to confidential HTC does not negatively affect the uptake of HTC services [33]-also states that names rather than codes can now be used in client records to facilitate referral. In contrast, Burkina Faso's policy stresses that test results cannot be shared with third parties, including colleagues, without the client's consent, and that the "principle of autonomy" demands that the client's name be replaced with a code [35]. Uganda's 2005 HCT policy is brief on the issue of confidentiality, stating that "HIV test results and patient records should be kept in a locked file with access limited to HCT personnel" [32]. It further states that the HCT site should not disclose results to anyone without the client's written consent, except when "a court requires it" [32]. Uganda's 2006 PMTCT policy does not mention confidentiality [36]. Malawi's 2008 PMTCT policy also has little to say about confidentiality; it espouses a couple- and familycentered model where health workers encourage shared confidentiality and disclosure among couples [37].

In Kenya and Burkina Faso, legislation-based on a template drafted by parliamentarians from 12 African countries to protect the rights of individuals infected or exposed to HIV [38]-has been passed requiring HIV-positive individuals to disclose to sexual partners. The 2008 Kenyan HTC policy is the most forceful on this point, stating that HTC workers should support their clients to disclose to sexual partners and that "if efforts to encourage the client or patient to disclose their HIV status fail, and

Table 3 Stigma variables

\begin{tabular}{l}
\hline Self-stigma \\
\hline "I sometimes feel worthless because I am HIV-positive" \\
\hline Enacted stigma \\
\hline "Have you personally ever been made to feel bad because of things people did or say to you on account of your HIV status?" \\
\hline "Did health workers ignore or avoid caring for you?" \\
\hline Reported community stigma \\
\hline "Have you heard of people who have been badly treated because they have HIV?" \\
\hline "Important that nobody knows results" \\
"Kept status secret"
\end{tabular}


the client or patient is placing a sexual partner or other person at risk, a medical practitioner may disclose someone's HIV status to their sexual partner or other person at risk" [33]. Refusal to notify one's partner is thus considered an infringement of the partner's right to health and well-being. Burkina Faso's 2008 HCT policy refers to law $\mathrm{N}^{\circ}$ 030-2008/AN (Article 7), which states that "any person living with HIV is required to promptly disclose their HIV status to their spouse or sexual partner" [35]. But unlike in Kenya, Burkina Faso's policy emphasizes that health workers cannot reveal clients' HIV status without their written consent; it encourages health workers to be "patient and understanding with respect to the positive partner who is reluctant to reveal their HIV status to their partner at first" [35].

\section{Women's views on HIV testing}

To explore views on HIV testing, we asked women whether it was hard to be tested. Most (84\%) said that it was not. When asked why, their responses reflected prior experience with testing and confidence in a likely HIVnegative result due to their awareness of HIV transmission routes. A 26 year old, HIV-negative married woman from urban Kenya said: "I had been faithful to my husband since testing negative in 2002." It was the same story for a young, HIV-negative married woman from rural Uganda, tested in a government hospital: "Because I had done it before and am also faithful to my husband." A 34 year old, HIV-negative married woman from rural Malawi: "Because I was thoroughly advised to be faithful, which I have been practicing, hence I had no fear."

Some client-respondents said that it was important for the woman to have "made up her mind" before the test. A young educated woman in urban Uganda who refused to be tested stated: "I felt I was not ready for the test that day." As HIV testing is now a common healthcare practice in all four countries, the offering of the test in antenatal care did not come as a surprise to our informants. In fact, $53 \%$ of our respondents had been tested more than once (see Table 1). $40 \%$ of pregnant women in Malawi, $34 \%$ in Kenya, 29\% in Uganda and 18\% in Burkina Faso had discussed having an HIV test with someone before coming to the clinic. In nearly all such cases, they talked to their husbands or partners. In Malawi, some women indicated that their husbands had "encouraged" them to be tested.

The qualitative findings suggest high levels of satisfaction with PMTCT. The services are valued because they help protect the health of the unborn child and because they provide a gateway to treatment. A young HIV-negative woman tested in a government hospital in rural Kenya for example asserted: "It is good... because I was pregnant and wanted to know my status and it is also a must for pregnant mothers." Another young woman tested in a government hospital in rural Uganda added: "It is good because if a mother is found positive she is always given treatment."

Two out of three HIV-positive women said they were glad to know their status and that good things happened to them since learning of their status. They gave various reasons for this. One woman reported that she had learnt to live positively and was able to prevent transmission to her child; another said that her health had improved and that she was still together with her husband. Another woman stated: "I started taking ARVs and I am healthy and nobody can suspect I am positive."

\section{Experiences with pre and post-test counseling}

In all four countries nearly all women (regardless of status) reported that they were treated well and that the PMTCT meeting was helpful overall (see Table 4). The rates for the 3 Cs variables (for the total sample) were above $80 \%$, with the exception of two variables: 'time to ask questions post-test' ( $78 \%$ of women were satisfied) and 'advised to discuss their status with others' (69\% of women reported that they were advised to disclose).

The statistical analysis reveals that there are no significant differences between the countries for the variables 'met with a counselor', 'explained how HIV is transmitted', 'counselor asked if you agreed to be tested', 'received results' and 'explained meaning of results'. However, statistically significant differences between the countries were observed for 'pre-test: explained the meaning of HIV positive or negative results', 'time to ask questions', 'explained that results will not be shared', and for advice on prevention, partner referral and disclosure. In Burkina Faso, scores appear to be particularly low on these 'comprehensiveness' variables: only $55 \%$ of respondents reported that during pre-test counseling the meaning of results was explained to them; only $67 \%$ said they were given time to ask questions pre-test; during post-test even fewer women were given a chance to ask questions (55\%); only $69 \%$ were given advice on prevention and only $27 \%$ of respondents were advised to discuss their status with others. Burkina Faso also has the lowest number of respondents who report that they are satisfied with the information received in PMTCT (77\% versus 95\% in Kenya and 94\% Uganda and $83 \%$ in Malawi). A high proportion of our respondents in Burkina have a low educational status (see Table 1), which could explain the lower reported quality of counseling in the country. Perhaps the health workers explain less because they do not expect that their clients will understand the information provided.

We expected that the HIV-positive women would evaluate the services more negatively: they require comprehensive counseling and may have many questions, while health workers are generally pressed for time. But this was not the case. Significantly higher percentages of HIV-positive women reported being given time to ask 
Table 4 Measures of pre-test and post-test counseling, confidentiality, consent, and satisfaction, by country

\begin{tabular}{|c|c|c|c|c|c|c|c|c|c|c|c|}
\hline & \multicolumn{2}{|c|}{ Burkina Faso } & \multicolumn{2}{|c|}{ Kenya } & \multicolumn{2}{|c|}{ Malawi } & \multicolumn{2}{|c|}{ Uganda } & \multicolumn{2}{|c|}{ Total } & \multirow[t]{2}{*}{$P$ value* } \\
\hline & No. & Col\% & No. & Col\% & No. & Col\% & No. & Col\% & No. & Col\% & \\
\hline \multicolumn{12}{|c|}{ Pre-test: meet with counselor before test } \\
\hline No & 3 & 2,88 & 5 & 6,76 & 11 & 8,03 & 9 & 9,78 & 28 & 6,88 & 0,220 \\
\hline Yes & 101 & 97,12 & 69 & 93,24 & 126 & 91,97 & 83 & 90,22 & 379 & 93,12 & \\
\hline \multicolumn{12}{|c|}{ Pre-test: explain how HIV is transmitted } \\
\hline No & 8 & 7,92 & 4 & 5,8 & 5 & 3,97 & 6 & 7,23 & 23 & 6,07 & 0,604 \\
\hline Yes & 93 & 92,08 & 65 & 94,2 & 121 & 96,03 & 77 & 92,77 & 356 & 93,93 & \\
\hline
\end{tabular}

Pre-test: explain the meaning of positive and negative results

\begin{tabular}{llllcccccccc}
\hline No & 46 & 45,54 & 5 & 7,25 & 8 & 6,35 & 4 & 4,82 & 63 & 16,62 & 0,000 \\
\hline Yes & 55 & 54,46 & 64 & 92,75 & 118 & 93,65 & 79 & 95,18 & 316 & 83,38 &
\end{tabular}

Pre-test: give time to ask questions in pre-test counseling

\begin{tabular}{llllllllllll}
\hline No & 33 & 32,67 & 7 & 10,14 & 8 & 6,35 & 15 & 18,07 & 63 & 16,62 & 0,000 \\
\hline Yes & 68 & 67,33 & 62 & 89,86 & 118 & 93,65 & 68 & 81,93 & 316 & 83,38 & \\
\hline
\end{tabular}

Found it difficult to test

\begin{tabular}{|c|c|c|c|c|c|c|c|c|c|c|c|}
\hline No & 79 & 79 & 55 & 79,71 & 113 & 91,13 & 70 & 84,34 & 317 & 84,31 & 0,044 \\
\hline Yes & 21 & 21 & 14 & 20,29 & 11 & 8,87 & 13 & 15,66 & 59 & 15,69 & \\
\hline
\end{tabular}

Consent: ask if you agreed to test

\begin{tabular}{lccccccccccc}
\hline No & 6 & 5,94 & 4 & 5,8 & 10 & 7,94 & 11 & 13,41 & 31 & 8,2 & 0,282 \\
\hline Yes & 95 & 94,06 & 65 & 94,2 & 116 & 92,06 & 71 & 86,59 & 347 & 91,8 & \\
\hline
\end{tabular}

Consent: explain that you had a choice to agree or refuse

\begin{tabular}{llllllllllll}
\hline No & 15 & 14,85 & 6 & 8,7 & 14 & 11,11 & 26 & 31,71 & 61 & 16,14 & 0,000 \\
\hline Yes & 86 & 85,15 & 63 & 91,3 & 112 & 88,89 & 56 & 68,29 & 317 & 83,86 & \\
\hline
\end{tabular}

Confidentiality: explain that results will not be shared

\begin{tabular}{llllllllllll}
\hline No & 27 & 27 & 8 & 11,59 & 4 & 3,17 & 4 & 4,82 & 43 & 11,38 & \\
\hline Yes & 73 & 73 & 61 & 88,41 & 122 & 96,83 & 79 & 95,18 & 335 & 88,62 & 0,000 \\
\hline \multicolumn{2}{l}{ Confidentiality: believe that } & results have been protected \\
\hline No & 16 & 15,38 & 12 & 16,22 & 9 & 6,67 & 24 & 26,97 & 61 & 15,17 & 0,001 \\
\hline Yes & 88 & 84,62 & 62 & 83,78 & 126 & 93,33 & 65 & 73,03 & 341 & 84,83 & \\
\hline
\end{tabular}

Post-test: received results

\begin{tabular}{|c|c|c|c|c|c|c|c|c|c|c|c|}
\hline No & 0 & 0 & 0 & 0 & 1 & 0,73 & 2 & 2,2 & 3 & 0,74 & 0,348 \\
\hline Yes & 104 & 100 & 74 & 100 & 136 & 99,27 & 89 & 97,8 & 403 & 99,26 & \\
\hline \multicolumn{12}{|c|}{ Post-test: information is sufficient } \\
\hline No & 24 & 23,08 & 4 & 5,41 & 8 & 5,88 & 15 & 16,85 & 51 & 12,66 & 0,000 \\
\hline Yes & 80 & 76,92 & 70 & 94,59 & 128 & 94,12 & 74 & 83,15 & 352 & 87,34 & \\
\hline \multicolumn{12}{|c|}{ Post-test: Explain meaning of result } \\
\hline No & 3 & 2,88 & 5 & 6,85 & 2 & 1,48 & 4 & 4,49 & 14 & 3,49 & 0,202 \\
\hline Yes & 101 & 97,12 & 68 & 93,15 & 133 & 98,52 & 85 & 95,51 & 387 & 96,51 & \\
\hline
\end{tabular}

Post-test: give advice on prevention

\begin{tabular}{|c|c|c|c|c|c|c|c|c|c|c|c|}
\hline No & 32 & 30,77 & 9 & 12,33 & 5 & 3,7 & 7 & 7,87 & 53 & 13,22 & 0,000 \\
\hline Yes & 72 & 69,23 & 64 & 87,67 & 130 & 96,3 & 82 & 92,13 & 348 & 86,78 & \\
\hline \multicolumn{12}{|c|}{ Post-test: advise to discuss status } \\
\hline No & 76 & 73,08 & 11 & 15,07 & 21 & 15,56 & 18 & 20,22 & 126 & 31,42 & 0,000 \\
\hline Yes & 28 & 26,92 & 62 & 84,93 & 114 & 84,44 & 71 & 79,78 & 275 & 68,58 & \\
\hline \multicolumn{12}{|c|}{ Post-test: advise partner referral } \\
\hline No & 28 & 26,92 & 11 & 15,07 & 8 & 5,93 & 7 & 7,87 & 54 & 13,47 & 0,000 \\
\hline Yes & 76 & 73,08 & 62 & 84,93 & 127 & 94,07 & 82 & 92,13 & 347 & 86,53 & \\
\hline
\end{tabular}

Post-test: time to ask questions 
Table 4 Measures of pre-test and post-test counseling, confidentiality, consent, and satisfaction, by country (Continued)

\begin{tabular}{|c|c|c|c|c|c|c|c|c|c|c|c|}
\hline No & 47 & 45,19 & 7 & 9,59 & 14 & 10,37 & 19 & 21,35 & 87 & 21,7 & 0,000 \\
\hline Yes & 57 & 54,81 & 66 & 90,41 & 121 & 89,63 & 70 & 78,65 & 314 & 78,3 & \\
\hline \multicolumn{12}{|c|}{ Satisfaction: post-test meeting was helpful overall } \\
\hline No & 1 & 0,96 & 3 & 4,05 & 3 & 2,21 & 7 & 7,87 & 14 & 3,47 & 0,054 \\
\hline Yes & 103 & 99,04 & 71 & 95,95 & 133 & 97,79 & 82 & 92,13 & 389 & 96,53 & \\
\hline \multicolumn{12}{|c|}{ Satisfaction: treated well overall } \\
\hline No & 0 & 0 & 6 & 8,11 & 3 & 2,21 & 26 & 29,55 & 35 & 8,73 & 0,000 \\
\hline Yes & 103 & 100 & 68 & 91,89 & 133 & 97,79 & 62 & 70,45 & 366 & 91,27 & \\
\hline
\end{tabular}

*Fischer exact test

questions, advised to discuss their status and advised to refer their partners. (see Table 5). Most of the HIV positive women were prescribed HIV medication (85\%), and around two-thirds were referred to a support group (see Table 6).

\section{A closer look at experiences with consent}

Does the scaling up of testing come at the expense of women knowing that they can opt out, as has been suggested by some earlier studies [39]? In our study, 92\% of PMTCT testers reported being asked if they agreed to

Table 5 Measures of post-test counseling, by HIV status

\begin{tabular}{|c|c|c|c|c|c|c|c|}
\hline & \multicolumn{2}{|c|}{ HIV-negative } & \multicolumn{2}{|c|}{ HIV-positive } & \multicolumn{2}{|c|}{ Total } & \multirow[t]{2}{*}{$P$-value* } \\
\hline & $\mathrm{N}$ & $\%$ & $\mathrm{~N}$ & $\%$ & $\mathrm{~N}$ & $\%$ & \\
\hline \multicolumn{8}{|c|}{ Post-test: received results } \\
\hline No & 2 & 0.6 & 1 & 1.6 & 3 & 0.7 & 0.403 \\
\hline Yes & 340 & 99.4 & 63 & 98.4 & 403 & 99.3 & \\
\hline \multicolumn{8}{|c|}{ Post-test: meaning of result explained } \\
\hline No & 13 & 3.8 & 2 & 3.2 & 15 & 3.7 & 1.000 \\
\hline Yes & 326 & 96.2 & 61 & 96.8 & 387 & 96.3 & \\
\hline \multicolumn{8}{|c|}{ Post-test: given advice on prevention } \\
\hline No & 50 & 14.7 & 4 & 6.3 & 54 & 13.4 & 0.105 \\
\hline Yes & 289 & 85.3 & 59 & 93.7 & 348 & 86.6 & \\
\hline \multicolumn{8}{|c|}{ Post-test: advised to discuss status ${ }^{* * *}$} \\
\hline No & 116 & 34.2 & 11 & 17.5 & 127 & 31.6 & 0.008 \\
\hline Yes & 223 & 65.8 & 52 & 82.5 & 275 & 68.4 & \\
\hline \multicolumn{8}{|c|}{ Post-test: advised to refer partner*** } \\
\hline No & 51 & 15 & 3 & 4.8 & 54 & 13.5 & 0.027 \\
\hline Yes & 288 & 85 & 59 & 95.2 & 347 & 86.5 & \\
\hline \multicolumn{8}{|c|}{ Post-test: time to ask questions ${ }^{* * *}$} \\
\hline No & 84 & 24.8 & 4 & 6.3 & 88 & 21.9 & 0.001 \\
\hline Yes & 255 & 75.2 & 59 & 93.7 & 314 & 78.1 & \\
\hline \multicolumn{8}{|c|}{ Satisfaction: post-test information was sufficient } \\
\hline No & 44 & 12.9 & 7 & 11.1 & 51 & 12.7 & 0.837 \\
\hline Yes & 296 & 87.1 & 56 & 88.9 & 352 & 87.3 & \\
\hline \multicolumn{8}{|c|}{ Satisfaction: post-test meeting was helpful overall } \\
\hline No & 13 & 3.8 & 1 & 1.6 & 14 & 3.5 & 0.706 \\
\hline Yes & 327 & 96.2 & 62 & 98.4 & 389 & 96.5 & \\
\hline \multicolumn{8}{|c|}{ Satisfaction: treated well overall } \\
\hline No & 30 & 8.9 & 5 & 7.9 & 35 & 8.7 & 1.000 \\
\hline Yes & 308 & 91.1 & 58 & 92.1 & 366 & 91.3 & \\
\hline
\end{tabular}

*two-sided Fisher's exact

**Denominator includes only respondents who indicated someone should be told

${ }^{* * *}$ significant difference between HIV-positive and HIV-negative respondents $(p<0.05)$ 
Table 6 Referral to care (HIV-positive PMTCT testers only)

\begin{tabular}{|c|c|c|}
\hline & \multicolumn{2}{|c|}{ HIV-positive } \\
\hline & No. & Col \% \\
\hline \multicolumn{3}{|c|}{ Referred for care } \\
\hline No & 19 & 31,1 \\
\hline Yes & 42 & 68,9 \\
\hline \multicolumn{3}{|c|}{ Prescribed medication for HIV } \\
\hline No & 9 & 14,8 \\
\hline Yes & 52 & 85,2 \\
\hline \multicolumn{3}{|c|}{ Referred to support group in post-test counseling } \\
\hline No & 23 & 37,7 \\
\hline Yes & 38 & 62,3 \\
\hline
\end{tabular}

testing; $84 \%$ were informed that they had the right to refuse. But women's experiences varied. A focus group discussion among women who had visited the Comprehensive Care Centre at a National Hospital in Kenya revealed that they could, at least in theory, refuse the HIV test: "You have a choice because you are not being forced." "If you do not want to be tested you can refuse." "There is no pressure to agree to be tested." But one respondent added: "The doctor is very powerful. If he tells you... you have to agree. If a doctor or any other medical person tells you to get tested, you do not have any other alternative but to get tested."

Other women reported that testing was mandatory. A married, 23 year old HIV-negative woman from rural Kenya, tested in a government Health Center, reported: "The nurse said it was mandatory when pregnant for PMTCT.” A married, HIV-negative woman from urban Malawi, tested in a government hospital, likewise reported: "We were told that HIV testing and counseling is a must for pregnant women these days: no HTC, no assistance from the doctor." It was the same for a young, uneducated, HIV-negative woman from urban Uganda, tested in a government hospital: "It was mandatory and a prerequisite for me to get treatment." In Burkina Faso, some women who refused the test were asked to sign a form, which was experienced as intimidating.

Many of our respondents did not oppose mandatory testing. When probed on who should be tested, pregnant women were most commonly mentioned, while other answers included unfaithful husbands and sex workers. But other respondents stressed that forcing women to test for HIV was not good. They reasoned that some individuals would not be able to handle the results that women should be able to choose for themselves, and that mandatory testing would scare women away from antenatal care. One rural uneducated woman in Malawi referred to a violation of rights: "It's not good since if she is not ready, her rights can be violated."
Opting out by pregnant women burdens health workers as they then have to keep track of the women and keep offering tests. As a matron in charge of a maternity in Kenya explained:

There are situations when antenatal mothers come and we are supposed to capture them for testing in their first visit, and when you give the information and counsel them especially on matters related to HIV, some will say, "look, sister, because I did not come with my husband, I would prefer to take the test when we are together." You just release her but on a subsequent visit she will repeat the same story about the husband not consenting, and she won't tell you she is declining. On another visit she lands on someone else's hands and not you who had counseled her, and the same story is repeated, not knowing that one had been counseled earlier and she is refusing indirectly. Finally, you realize that the mother is approaching delivery and has not been tested, like yesterday we had one, she kept on refusing to take the test, one of the counselors called me and narrated the story, we went to the mother and told her to sign that she has refused to take the test.... When we meet such clients we do continue counseling, we never get tired until the client agrees or disagrees...

Some health workers revealed that they deal with the challenge of "capturing" women by telling them that the test is mandatory: "They accept once you explain to them that the test is mandatory at ANC", explained an ANC counselor in a Kenyan health centre. An ANC nurse in a Ugandan health center likewise stated: "We talk to them about HIV testing, we tell them about the benefits, we then tell them that it is a government policy for all pregnant mothers to test."

\section{Stigma and confidentiality}

Most HIV-positive women (79\%) reported that they generally kept their HIV status secret. When probed about stigma, one out of five respondents reported that they felt worthless due to being HIV-positive; an equal proportion felt guilty. One out of four had been personally made to feel bad, and around half had heard about other HIV-positive people being treated badly. Only one respondent reported that health workers avoided caring for her (see Table 7).

The large majority (85\%) felt that the health workers and counselors respected their desire for confidentiality by protecting their results (See Table 4). An example of breached confidentiality was given by a 22 year old woman from Malawi, who tested positive in a rural health center when she was pregnant in 2008. A counselor from a support group had disclosed her status to 
Table 7 Measures of stigma and disclosure (HIV-positive PMTCT testers only)

\begin{tabular}{|c|c|c|}
\hline & $\mathrm{N}$ & $\%$ \\
\hline \multicolumn{3}{|l|}{ Disclosure } \\
\hline \multicolumn{3}{|l|}{ Important that nobody knows results } \\
\hline Very important & 53 & 85.5 \\
\hline Somewhat important & 4 & 6.5 \\
\hline Not important & 5 & 8.1 \\
\hline \multicolumn{3}{|l|}{ Kept status secret } \\
\hline$\overline{\text { No }}$ & 13 & 20.6 \\
\hline Yes & 50 & 79.4 \\
\hline \multicolumn{3}{|l|}{ Told someone results } \\
\hline No & 11 & 17.5 \\
\hline Yes & 52 & 82.5 \\
\hline \multicolumn{3}{|l|}{ Told partner results* } \\
\hline No & 32 & 62.7 \\
\hline Yes & 19 & 37.3 \\
\hline \multicolumn{3}{|l|}{ Told family results* } \\
\hline No & 19 & 37.3 \\
\hline Yes & 32 & 62.7 \\
\hline \multicolumn{3}{|l|}{ Told friend results* } \\
\hline$\overline{\mathrm{No}}$ & 46 & 90.2 \\
\hline Yes & 5 & 9.8 \\
\hline \multicolumn{3}{|l|}{ Stigma and discrimination } \\
\hline \multicolumn{3}{|l|}{ Self-Stigma: } \\
\hline \multicolumn{3}{|l|}{ feel worthless because HIV+ } \\
\hline Undecided/disagree/strongly disagree & 48 & 80 \\
\hline Strongly agree/agree & 12 & 20 \\
\hline \multicolumn{3}{|l|}{ feel guilty because HIV+ } \\
\hline Undecided/disagree/strongly disagree & 47 & 81 \\
\hline Strongly agree/agree & 11 & 19 \\
\hline \multicolumn{3}{|l|}{ Enacted stigma/discrimination: } \\
\hline \multicolumn{3}{|l|}{ personally been made to feel bad } \\
\hline$\overline{\text { No }}$ & 44 & 74.6 \\
\hline Yes & 15 & 25.4 \\
\hline \multicolumn{3}{|c|}{ health workers ignored or avoided caring for you } \\
\hline No & 59 & 98.3 \\
\hline Yes & 1 & 1.7 \\
\hline
\end{tabular}

Reported community stigma:

heard of people who have been badly treated

\begin{tabular}{lll}
\hline No & 31 & 51.7 \\
\hline Yes & 29 & 48.3
\end{tabular}

Good things happened because status known

\begin{tabular}{lll}
\hline No & 20 & 34.5 \\
\hline Yes & 38 & 65.5 \\
\hline
\end{tabular}

*Denominator is persons who've told someone their status others in the community without her consent: "The counselor of publicized at my village that I've been found positive, which has left many people to know though I took it as confidential."

\section{Low levels of partner disclosure}

In our study, $83 \%$ of the HIV-positive pregnant women had disclosed to someone. Mostly they disclosed to family members (63\%), usually their sister and/or parents. Only one in three had disclosed to their partners, while one in ten had disclosed to a friend.

Given post-test counseling's emphasis on disclosing to partners, it was surprising that only one-third of the HIV-positive pregnant women had done so. Analysis of the open-ended questions revealed that some of these women were divorced or widowed. But many others reported that they found it very difficult to tell their husbands, out of fear of being blamed, abused and/or abandoned. A 22 year old woman, tested in an urban Kenyan health center and encouraged by health workers to disclose to her husband and convince him to test, stated: "My spouse denied that I was positive and did not take the test. He thought then and still thinks it's a joke." A 29 year old pregnant woman, tested in a government hospital in rural Kenya who has known her HIV-positive status for 16 months said she was afraid to disclose because she expected her husband to beat her up and leave her. It was a similar story for a 19 year old pregnant woman in Uganda; she had learnt her HIV-positive status 3 months prior to our interview and had not disclosed to anybody, including her partner: "my husband would divorce me even if he knows that he is infected." Only a few of the women that we interviewed in Uganda and Kenya were a member of a support group at the time of our interview. A 25 year old HIV-positive woman was encouraged by health workers at an urban health center in Burkina Faso to disclose to her parents. She disclosed to her parents as well as to her brother and husband. Disclosing to her husband did not go smoothly: "I have had to fight with my husband, he told me he had someone else, he would chase me away because I have AIDS and he doesn't. He also told his friends and other relatives that I have AIDS." She joined a support group, as did two of the other six HIV-positive mothers in Burkina Faso.

We interviewed 34 women who tested HIV-positive in Malawi, more than in any other country. Relatively many (13 out of 34) had joined a support group. Eight of them reported having disclosed to their partners. One 30 year old woman described how her husband "chased me out of our house for a week" when she disclosed to him. She is not intending to disclose to anyone else because she 
doesn't want to be laughed at. A 35 year old woman reported: "my husband left me for another wife." Another woman was divorced after she disclosed. Staff at a rural health center had suggested that she should disclose to her mother and relatives; she feared that they wouldn't accept the results and decided to disclose to her husband instead. He accused her, demanded to know how she got infected, and subsequently left her. But in some cases, the husband grew more accepting over time. One young woman reported that her husband was at first angry and accused her, but now treats her better. A 40 year old woman, tested in an urban government hospital, explained that she disclosed because "it was good to let him know." He is supportive now but gets worried when she falls ill with, for example, malaria. She will not disclose to others because "people might start gossiping whenever they know my status, as a result I will lack peace of mind."

The in-depth interviews revealed that disclosure is not always direct. Some women disclosed by encouraging their partners to go with them to couple's counseling and testing; others disclosed by not hiding their antiretroviral drugs.

\section{Discussion}

This four-country study reveals that pregnant women are generally satisfied with HTC in antenatal care. It is valued because it helps protect the health of the unborn child and because it provides a gateway to treatment. Women generally reported that they did not find the HIV test hard to take. Around half of our respondents were repeat-testers and knew what to expect.

The results of our quantitative analysis reveal that overall the majority of pregnant women attending antenatal care (80-90\%) report that they were explained the meaning of the tests, explained how HIV can be transmitted, given advice on prevention, encouraged to refer their partners for testing, and given time to ask questions. In all four countries, nearly all women (regardless of their HIV status) reported that they were treated well and that the meeting was helpful overall.

The policy analysis shows that counselors in all countries are expected to ask for consent before conducting an HIV test, but that there are differences in HTC policy regarding the comprehensiveness of pre- and post-test counseling and the requirements of confidentiality. The statistical analysis reveals that there are no significant differences between the countries for the 3Cs variables 'met with a counselor', 'explained how HIV is transmitted', 'counselor asked if you agreed to be tested', 'received results' and 'post test: explained meaning of results', reflecting convergence in policy between the countries on these 'minimal' elements of HTC. However statistically significant differences between countries were observed for other 3Cs variables, including 'pre-test: explained meaning of results', 'time to ask questions' and advice on prevention, disclosure and partner referral. These results reveal that the 'comprehensiveness' of the HTC in ante-natal care services varies between the countries (and probably also by facility within the countries, but because of sample size limitations we could not test for this). Our findings suggest that the quality of counseling is lowest in Burkina Faso, where fully $46 \%$ of women said that they were not explained the meaning of HIV positive and HIV negative test results in pre-test counseling, while post-test $45 \%$ were not given a chance to ask questions, $31 \%$ were not given advice on prevention, and $73 \%$ of respondents were not advised to discuss their status with others. These findings may reflect relatively low educational levels among respondents in Burkina Faso and health workers assuming that uneducated women will not understand the information they provide. An earlier study on the quality of HIV testing and counseling care in 14 Burkina Faso health facilities [40] reported remarkably similar findings: $46 \%$ of clients were not explained the significance of positive or negative test results in pre-test counseling, and only $44 \%$ of clients were not given a chance to ask questions. The limited attention to disclosure in the counseling sessions in Burkina Faso could be related to the emphasis in the Burkina Faso policy on confidentiality. The Burkina Faso HCT policy states that health workers need to be patient and understanding when an HIV positive person does not want to disclose.

While our quantitative assessment of consent showed that pregnant women in all four countries have the option to refuse the test, the qualitative findings suggest that some women feel it is an "offer they cannot refuse." Different views prevail on mandatory testing for HIV. In Uganda and Kenya, we found some providers-and some women-supporting it for pregnant women; underlying their stance is the moral imperative to protect the unborn child. Many women in Malawi and Burkina Faso, in line with these countries' policies, asserted that women should have the right to refuse HIV testing.

We found that healthcare workers in the four countries provided post-test counseling of a significantly higher standard to HIV-positive women than to their HIV-negative counterparts. Even so, 20\% of the HIVpositive women in our study reported that they felt guilty or worthless, suggesting that self-stigma continues despite increased access to anti-retroviral treatment in all four countries.

Compared to other studies [41,42] we found relatively high levels of disclosure: $83 \%$ of our HIV-positive respondents had disclosed to someone, usually a family member. But disclosure was selective. Women simultaneously told us that they generally kept their status 
secret. Despite the availability of anti-retroviral treatment, they continue to fear stigma and social suffering if word about their HIV status spreads in the community. As Bond [43] points out, women appear to juggle the pragmatic advantages of disclosing to a limited circle of people with the importance of maintaining their moral integrity. Their underlying fear is to be blamed for being promiscuous, or for introducing the virus into the family. A recent cross-sectional study in rural Kenya [44] found that $37 \%$ of pregnant women accepting an HIV test feared that they would be rejected and/or physically abused by their partners if they tested positive and their partners found out.

Only $37 \%$ of the HIV-positive women in our study had disclosed to their partners, despite the emphasis on partner disclosure in post-test counseling in all four countries. Analysis of the qualitative data revealed that disclosure can create serious rifts with partners; some women were abandoned or divorced by their husbands. These findings confirm those from earlier studies on the influence of anticipated rejection and violence from boyfriends and husbands on partner disclosure [45-50].

The risk of intimate partner violence is a crucial issue that needs to be addressed in PMTCT programs. Our findings suggest that enacted stigma is still prominent among HIV-positive pregnant women in Sub-Saharan Africa, despite the widespread availability of ART. Roura et al. [49] point out that this is due to ART availability only marginally affecting the discourse of blame that lies behind enacted stigma (the authors argue that self-stigma has declined). Women who test positive in PMTCT generally find out when they are not yet ill-earlier than their male sexual partners who tend to be tested when a health worker suggests a diagnostic HIV test. Many HIV-positive pregnant women thus fear being blamed for introducing the infection into the family. A study in rural Malawi found that some women waited until their husband showed signs of illness before disclosing their positive status [51].

While our survey found healthcare workers to be systematically advising pregnant women to refer their husbands for testing, the in-depth interviews revealed that partners rarely come in for testing. This may be due to men's reluctance to be seen in antenatal clinics, which are seen as part of a 'female' domain; attending one would risk questions from peers about one's masculinity [52]. In countries such as Burkina Faso and Kenya where HIV transmission is criminalized, HIV-positive pregnant women could theoretically even be prosecuted for infecting their husbands and children. The potential adverse effects of disclosure for women, particularly during the socially vulnerable period of pregnancy, suggest a need for accompanying measures that promote early testing among men. This is further supported by the findings that men tend to more often disclose to their partners than women [53], and that knowing one's partner's status facilitates disclosure [54].

Now that HIV testing is being scaled up in Burkina Faso, Kenya, Malawi and Uganda, better integration of PMTCT with other modes of testing, such as homebased or workplace HTC, should be possible. The Ugandan MATCH country study found home-based testing to facilitate disclosure [55-58]. If accompanied by good follow-up medical care, home-based testing enables early treatment for both men and women, allowing them to plan for PMTCT before pregnancy.

The current study contributes to the development of methods to measure consent, counseling and confidentiality procedures (the $3 \mathrm{C}$ 's) in HIV testing. While such studies are common in family planning [59-61], in HIV testing the emphasis has been on measuring the acceptability and uptake of follow-up medical care, with relatively little attention to the interpersonal processes involved.

One limitation of the study is its purposive sampling frame. Our sample was made up of purposively selected antenatal care facilities in the capital city and one rural province/district in all four countries. We aimed to include a range of facilities in the sample to explore diversity in HTC practice. A systematic sample of respondents was taken in each facility, but adjustments in the sampling procedures were made when attendance was lower than expected. The number of ante-natal care clients interviewed per facility varied between 5 and 30 . The samples are thus not representative of the population of ante-natal care clients in the countries concerned. Because of low numbers of PMTCT respondents per facility, we could not conduct multi-level analysis aimed at analyzing the effects of country level policies, institutional practices and individual factors on client satisfaction with PMTCT services. Moreover, the data were collected in 2008/2009. While this is more recent than most published studies, the findings do not necessarily reflect the current situation in the countries concerned.

Another limitation of the study is that the interviews were conducted within health facilities. It is possible that the relatively high levels of satisfaction reported in our study were caused by desirability bias; several other studies have shown that clients are reluctant to express negative opinions of services when interviewed at health facilities [62,63]. By adding open-ended questions to the interview and by conducting additional key informant interviews in communities, we were able to triangulate the findings and overcome this limitation. For example, the quantitative data suggested high levels of disclosure, while the answers of HIV-positive pregnant women to the open-ended questions revealed that disclosure is 
selective and that secrecy remains the norm for fear of stigma and social suffering.

Finally, the relatively small number of HIV-positive individuals included in the study $(\mathrm{N}=63)$ and their uneven distribution (half are from Malawi) does not allow for quantitative analysis of the differences in experience of HIV-positives by country. We have therefore highlighted our qualitative findings for this sub-population, pointing to the common concerns of HIV-positive pregnant women across the diverse institutional and country settings.

\section{Conclusion}

Analysis using mixed methods is important to provide not only measurements of perceived quality, but also insight into women's experiences of these services, as well as the barriers that remain in efforts to stop transmission of HIV from mother to child. Our study reveals that women are generally satisfied with PMTCT services, but that there is a lack of clarity surrounding the necessity and meaning of consent. In Burkina Faso, the quality of counseling was found to be sub-optimal. More in-depth studies are needed to further elucidate the dynamics within PMTCT to understand why, in some cases, women are not provided with good quality care.

The study further found that the majority $(63 \%)$ of HIV-positive pregnant women do not disclose their status to partners. Some women, who did disclose, faced rejection by their partners and/or divorce. Moreover, $20 \%$ of women experienced self-stigma, while $25 \%$ reported that they were personally made to feel bad because of their HIV status. These findings suggest that the PMTCT strategy of testing pregnant women in antenatal care-and subsequently asking them to refer their partners-needs to be rethought. Promoting testing options that reach men might reduce (self-)blame among women for introducing the disease into their families and promote disclosure. If accompanied by good follow-up medical care, home-based testing enables early treatment for both men and women, allowing them to plan for PMTCT before pregnancy.

\footnotetext{
Acknowledgements

This project was supported by a grant from the National Institutes of Health (5 R01 HD053268-05, PI: Carla Obermeyer). This support is gratefully acknowledged. We thank the women who participated in the study, especially the HIV-positive women who shared their stories with us. We thank John Kinsman for providing technical support to the MATCH study, and Takeo David Hymans for his excellent editorial support in the final stages of this manuscript.
}

\section{Author details}

${ }^{1}$ Amsterdam Institute for Social Science Research, University of Amsterdam, Amsterdam, the Netherlands. ${ }^{2}$ Research for Equity and Community Health Trust, Lilongwe, Malawi. ${ }^{3}$ National AIDS/STD Control Programme, Ministry of Health, Nairobi, Kenya. ${ }^{4}$ Université Paul Cézanne d'Aix-Marseille/Institut de Recherche pour le Développement, Dakar, Sénégal. ${ }^{5}$ Makerere University
Department of Social Work/Child Health and Development Centre, Kampala, Uganda. Fellow at Wissenschaftskolleg, 2010-11, Berlin. ${ }^{6}$ Programme d'Appui au Monde Associatif \& Communautaire de Lutte Contre le VIH/SIDA, Ouagadougou, Burkina Faso. 7 Department of Society, Human Development, and Health, Harvard School of Public Health, Boston, USA. ${ }^{8}$ Makerere University School of Public Health, Kampala, Uganda. ${ }^{9}$ Faculty of Health Sciences, American University of Beirut, Beirut, Lebanon.

\section{Authors' contributions}

Concept protocol: This analysis is part of a larger project, for which the research proposal was developed by $\mathrm{CO}$. $\mathrm{AH}$ designed the analysis of a subset of data on which this paper is based.

Data collection: $\mathrm{CO}$ and $\mathrm{AH}$ jointly developed the quantitative and qualitative research instruments in consultation with researchers $(G B, P C, A D$, DK, OK and RW) from the country teams. Data collection was done by the country researchers (GB, PC, DK, OK and RW) together with research assistants.

Data analysis: MN conducted the quantitative analysis with input from $\mathrm{AH}$; $\mathrm{EV}$ and $\mathrm{AH}$ conducted the qualitative analysis. $\mathrm{AH}$ and $\mathrm{EV}$ were responsible for the triangulation of results, in which some of the quantitative findings were nuanced with qualitative insights. The conclusions were validated with the country researchers (GB, PC, DK, OK and RW).

Manuscript draft: The manuscript was written by $\mathrm{AH}$ with substantial contributions by EV. All authors commented on the first draft of the paper. Comments were incorporated in the final draft, which was sent around for approval before submitting.

\section{Competing interests}

The authors declare that they have no competing interests.

Received: 22 July 2011 Accepted: 11 January 2012

Published: 11 January 2012

\section{References}

1. WHO/UNAIDS/UNICEF: Towards universal access: scaling up priority HIV/ AIDS interventions in the health sector: progress report 2010. Geneva: World Health Organization; 2010.

2. United Nations: Political declaration on HIV/AIDS: intensifying our efforts to eliminate HIV/AIDS. United Nations general assembly, 65th session, agenda item 10. Resolution adopted by the General assembly on 10th June 2011. New York: United Nations; 2011.

3. WHO/UNAIDS: Recommendations on the safe and effective use of shortcourse ZDV for prevention of mother-to-child transmission of HIV. Wkly Epidemiol Rec 1998, 73:313-320.

4. Msellati P: Improving mothers' access to PMTCT programs in West Africa: a public health perspective. Soc Sci Med 2009, 69(6):807-812.

5. WHO: Strategic approaches to the prevention of HIV infection in infants: report of a WHO Meeting. Morges, Switzerland; 2002, 20-22.

6. UNFPA: Call to action: towards an HIV-free and AIDS-free generation. Prevention of Mother to Child Transmission (PMTCT) high level global partners forum. Abuja, Nigeria; 2005.

7. UNICEF: Evaluation of United Nations-supported pilot projects for the prevention of mother-to-child transmission of HIV. 2003.

8. UNAIDS/WHO: Policy Statement on HIV Testing. Geneva: United Nations and World Health Organization; 2004.

9. Yeatman SE: Ethical and public health considerations in HIV counseling and testing: policy implications. Stud Fam Plann 2007, 38(4):271-278.

10. Bayer R, Edington C: HIV testing, human rights, and global AIDS policy: exceptionalism and its discontents. J Health Polit Policy Law 2009, 34(3):301-323.

11. Hardon A, Kageha E, Kinsman J, Kyaddondo D, Wanyenze R, Obermeyer CM: Dynamics of care, situations of choice: HIV tests in times of ART. Med Anthropol 2011, 30(2):183-201.

12. Nakanjako D, Kamya M, Daniel K, Mayanja-Kizza H, Freers J, Whalen C, Katabira E: Acceptance of routine testing for HIV among adult patients at the medical emergency unit at a National Referral Hospital in Kampala, Uganda. AIDS Behav 2007, 11(5):753-758.

13. Cockcroft A, Andersson N, Milne D, Mokoena T, Masisi M: Community views about routine HIV testing and antiretroviral treatment in Botswana: signs of progress from a cross sectional study. BMC International Health and Human Rights 2007, 7(1):5. 
14. Manzi M, Zachariah R, Teck R, Buhendwa L, Kazima J, Bakali E, Firmenich P, Humblet P: High acceptability of voluntary counselling and HIV-testing but unacceptable loss to follow up in a prevention of mother-to-child HIV transmission programme in rural Malawi: scaling-up requires a different way of acting. Trop Med Int Health 2005, 10(12):1242-1250.

15. Wanyenze RK, Nawavvu C, Namale AE, Vlayanja B, Bunnell R, Abang B, Amanyire G, Sewankambo NK, Kamya MR: Acceptability of routine HIV counselling and testing, and HIV seroprevalence in Ugandan hospitals. Bull World Health Org 2008, 86(4):302-309.

16. Weiser SD, Heisler M, Leiter K, Percy-de Korte F, Tlou S, DeMonner S, Phaladze N, Bangsberg DR, lacopino V: Routine HIV testing in Botswana: a population-based study on attitudes, practices, and human rights concerns. PLoS Med 2006, 3(7):1013-1022.

17. Perez F, Mugore L, Engelsmann B, Ndoro T, Dabis F: An assessment of the understanding of the offer of routine HIV testing among pregnant women in rural Zimbabwe. Aids Care: Psychol Socio-Med Aspects AIDS/HIV 2008, 20(6):660-666.

18. Bajunirwe B, Muzoora M: Barriers to the implementation of programs for the prevention of mother to child transmission of HIV: a cross-sectional survey in rural and urban Uganda. AIDS Res Ther 2005, 2:10.

19. Bwirire LD, Fitzgerald M, Zachariah R, Chikafa V, Massaquoi M, Moens M, Kamoto K, Schouten EJ: Reasons for loss to follow-up among mothers registered in a prevention-of-mother-to-child transmission program in rural Malawi. Trans R Soc Trop Med Hyg 2008, 102(12):1195-1200.

20. Coulibaly M, Noba V, Rey JL, Msellati P, Ekpini R, Chambon JF: Assessment of a programme of prevention of mother-to-child transmission of HIV in Abidjan, Ivory Coast (1999-2002). Méd Trop 2005, 66(1):53-58.

21. Etiebet MA, Fransman D, Forsyth B, Coetzee N, Hussey G: Integrating prevention of mother-to-child HIV transmission into antenatal care: learning from the experiences of women in South Africa. AIDS Care: Psychol Socio-Med Aspects AIDS/HIV 2004, 16(1):37-46.

22. Painter TM, Diaby KL, Matia DM, Lin LS, Sibailly TS, Kouassi MK, Ekpini ER, Roels TH, Wiktor SZ: Women's reasons for not participating in follow up visits before starting short course antiretroviral prophylaxis for prevention of mother to child transmission of HIV: qualitative interview study. Br Med J 2004, 329(7465):543-546.

23. Delva W, Mutunga L, Quaghebeur A, Temmerman M: Quality and quantity of antenatal HIV counselling in a PMTCT programme in Mombasa, Kenya. AIDS Care: Psychol Socio-Med Aspects of AIDS/HIV 2006, 18(3):189-193.

24. Creek TL, Ntumy R, Seipone K, Smith M, Mogodi M, Smit M, Legwaila K, Molokwane I, Tebele G, Mazhani L, et al: Successful introduction of routine opt-out HIV testing in antenatal care in Botswana. J Acquir Immune Defic Syndr 2007, 45(1):102-107.

25. WHO/UNAIDS: Guidance on provider-initiated HIV testing and counselling in health facilities. Geneva: World Health Organization; 2007.

26. CDC: Centers for Disease Control and Prevention revised recommendations for HIV testing of adults, adolescents, and pregnant women in health-care settings. Morb Mortal Wkly Rep 2006, 55(RR14):1-17.

27. WHO: A Handbook for improving HIV testing and counselling services: field-test version. Geneva: World Health Organization; 2010.

28. WHO/UNAIDS: Scaling-up HIV Testing and Counselling Services: A Toolkit for Programme Managers. Geneva: World Health Organization and the Joint United Nations Programme on HIV/AIDS; 2005.

29. Poljak M, Smit E, Ross J: 2008 European Guideline on HIV Testing. Int J STD AIDS 2009, 20:77-83.

30. Cohan D, Gomez E, Greenberg M, Washington S, Charlebois ED: Patient perspectives with abbreviated versus standard pre-test HIV counseling in the prenatal setting: a randomized-controlled, non-inferiority trial. PLOS ONE 2009, 4(4):e5166.

31. Obermeyer CM, Bott S, Carrieri P, Parsons M, Pulerwitz J, Rutenberg N, Sarna A: HIV Testing, Treatment and Prevention: Generic Tools for Operational Research. Geneva: World Health Organization; 2009.

32. Uganda Ministry of Health: Uganda National Policy Guidelines for HIV Counseling and Testing. Kampala: Ministry of Health; 2005.

33. Kenya Ministry of Public Health and Sanitation: Guidelines for HIV testing and counselling and Kenya. Nairobi: National AIDS and STI Control Programme, NASCOP; 2008.

34. Malawi Ministry of Health: HIV Testing and Counseling (HTC). The 5 year plan to scale up HIV testing and counselling services in Malawi 20062010. Lilongwe: Ministry of Health; 2006.
35. Burkina Faso Ministry of Health: Burkina Faso National HIV Counseling and Testing Guidelines (Normes et directives nationales de conseil depistage de l'infection a VIH au Burkina Faso). Quagadougou: Ministry of Health; 2008.

36. Uganda Ministry of Health: Policy guidelines for mother to child transmission, Revised Edition, August 2006. Kampala: Ministry of Health; 2006.

37. Malawi Ministry of Health: Prevention of mother to child transmission of HIV and paediatric HIV care guidelines, Second Edition, July 2008. Lilongwe: Ministry of Health; 2008.

38. Sanon P, Kabore S, Wilen J, Smith SJ, Galvao J: Advocating prevention over punishment: the risks of HIV criminalization in Burkina Faso. Reprod Health Matters 2009, 17(34):146-153.

39. Ujiji OA, Rubenson B, llako F, Marrone G, Wamalwa D, Wangalwa G, Ekstrom AM: Is 'opt-out HIV testing' a real option among pregnant women in rural districts in Kenya? BMC Public Health 2011, 11:151.

40. Obermeyer CM, Sankara A, Bastien V, Parsons M: Gender and HIV testing in Burkina Faso: An exploratory study. Soc Sci Med 2009, 69(6):877-884.

41. Bott S, Obermeyer C: Gender and HIV disclosure in sub-Saharan Africa: a review of policies and practices. J Soc Aspects of HIV-AIDS;

42. Maman S, Medley A: Gender dimensions of HIV status disclosure to sexual partners: rates, barriers and outcomes. A review paper. Geneva: World Health Organization; 2004.

43. Bond VA: It is not an easy decision on HIV, especially in Zambia: opting for silence, limited disclosure and implicit understanding to retain a wider identity. AIDS Care 2010, 22(sup1):6-13.

44. Turan J, Bukusi E, Onono M, Holzemer W, Miller S, Cohen C: HIV/AIDS stigma and refusal of HIV testing among pregnant women in rural Kenya: results from the MAMAS Study. Aids Behav 2011, 15(6):1111-1120.

45. Deribe K, Woldemichael K, Njau BJ, Yakob B, Biadgilign S, Amberbir A: Gender differences regarding barriers and motivators of HIV status disclosure among HIV-positive service users. I Soc Aspects of HIV-AIDS 2010, 7(1):30-39.

46. Gaillard P, Melis R, Mwanyumba F, et al: Vulnerabilty of women in an African setting: lessons from mother-to-child transmission prevention programs. AIDS 2002, 16(6):937-939.

47. Obermeyer Makhlouf C, Baijal P, Pegurri E: Facilitating HIV disclosure across diverse settings: a review. Am J Public Health 2011, 101(6):1011-1023.

48. Medley A, Garcia-Morena C, McGill S, Maman S: Rates, barriers and outcomes of HIV-serostatus disclosure among women in developing countries: implications for prevention of mother-to-child transmission in developing countries. Bull World Health Org Supp/ 2004, 82(4):299-307.

49. Roura M, Urassa M, Busza J, Mbata D, Wringe A, Zaba B: Scaling up stigma? The effects of antiretroviral roll-out on stigma and HIV testing. Early evidence from rural Tanzania. Sex Transm Infect 2009, 85(4):308-312.

50. Visser M, Neufeld S, de Villiers A, Makin JD, Forsyth BWC: To tell or not to tell: South African women's disclosure of HIV status during pregnancy. AIDS Care 2011, 20(9):1138-1145.

51. Parrott FR, Mwafulirwa C, Ngwira B, Nkhwazi S, Floyd S, et al: Combining qualitative and quantitative evidence to determine factors leading to late presentation for antiretroviral therapy in Malawi. PLOS ONE 2011, 6(11):e27917.

52. Falnes F, Moland KM, Tylleskär T, de Paoli MM, Msuya SE, Engebretsen IMS: "It is her responsibility": partner involvement in the prevention of mother to child transmission of HIV programmes, northern Tanzania. J Int AIDS Soc 2011, 14(21):1-12.

53. Anglewicz $P$, Chintsanya J: Disclosure of HIV status between spouses in rural Malawi. AIDS Care 2011, 23(8):998-1005.

54. King R, Katuntu D, Lifshay J, Packel J, Batanwita R, Nakayiw S, Abang B, Babirye F, Lindkvist P, Johansson J, Bunnel R: Processes and outcomes of HIV serostatus disclosure to sexual partners among people living with HIV in Uganda. AIDS Behav 2008, 12:232-243.

55. Helleringer S, Kohler HP, Frimpong JA, Mkandawire J: Increasing uptake of HIV testing and counseling among the poorest in Sub-Saharan countries through home-based service provision. J Acquir Immune Defic Syndr 2009, 51(2):185-193.

56. Kyaddondo D, Wanyenze R, Kinsman J, Hardon A: Home-based HIV counseling and testing facilitates disclosure: client experiences in Eastern Uganda. Submitted to AIDSCare 2011. 
57. Matovu JKB, Kigozi G, Nalugoda F, Wabwire-Mangen F, Gray RH: The Rakai Project counselling programme experience. Trop Med Int Health 2002, 7(12):1064-1067.

58. Wolff B, Nyanzi B, Katongole G, Ssesanga D, Ruberantwari A, Whitworth J: Evaluation of a home-based voluntary counselling and testing intervention in rural Uganda. Health Policy Plan 2005, 20(2):109-116.

59. Bruce J: Fundamental elements of the quality of care - a simple framework. Stud Fam Plann 1990, 21(2):61-91.

60. Hyman A, Kumar A: A woman-centered model for comprehensive abortion care. Int J Gynecol Obstet 2004, 86(3):409-410.

61. Williams T, Schutt-Aine J, Cuca Y: Measuring family planning service quality through client satisfaction exit interviews. Int Fam Plan Perspect 2000, 26(2):63-7.

62. Avis $\mathrm{M}$, Bond $\mathrm{M}$, Arthur $\mathrm{A}$ : Questioning patient satisfaction: an empirical investigation in two outpatient clinics. Soc Sci Med 1997, 44(1):85-92.

63. León FR, Lundgren R, Huapaya A, Sinai I, Jennings V: Challenging the courtesy bias interpretation of favorable clients' perceptions of family planning delivery. Eval Rev 2007, 31(1):24-42.

\section{Pre-publication history}

The pre-publication history for this paper can be accessed here: http://www.biomedcentral.com/1471-2458/12/26/prepub

doi:10.1186/1471-2458-12-26

Cite this article as: Hardon et al:: Women's views on consent, counseling and confidentiality in PMTCT: a mixed-methods study in four African countries. BMC Public Health 2012 12:26.

\section{Submit your next manuscript to BioMed Central and take full advantage of:}

- Convenient online submission

- Thorough peer review

- No space constraints or color figure charges

- Immediate publication on acceptance

- Inclusion in PubMed, CAS, Scopus and Google Scholar

- Research which is freely available for redistribution

Submit your manuscript at www.biomedcentral.com/submit 